OPEN ACCESS

Edited by:

Masoud Mozafari,

University of Toronto, Canada

Reviewed by:

Xiaogang Luo,

Wuhan Institute of Technology, China

Sheela Chandren,

University of Technology Malaysia,

Malaysia

*Correspondence:

Hong-jing Cui

cuihongjing@gdmu.edu.cn

Jian-tao Lin

41204319@qq.com

Ya-xin Sun

yaxin598@126.com

tThese authors have contributed equally to this work

Specialty section:

This article was submitted to

Biomaterials,

a section of the journal

Frontiers in Materials

Received: 04 January 2021

Accepted: 24 May 2021

Published: 15 June 2021

Citation:

Cui X-g, Chen H, Ye Q-b, Cui X-y, Cui X-j, Cui H-j, Shen G-z, LiM-j, Lin J-t and Sun $Y-x$ (2021) Porous Titanium Dioxide Spheres for Drug Delivery and

Sustained Release.

Front. Mater. 8:649237.

doi: 10.3389/fmats.2021.649237

\section{Porous Titanium Dioxide Spheres for Drug Delivery and Sustained Release}

\author{
Xin-gang Cui ${ }^{1 \dagger}$, Hua Chen ${ }^{2 \dagger}$, Qing-bang Ye ${ }^{3 t}$, Xin-yu Cui ${ }^{1}$, Xiao-jing Cui ${ }^{4}$, Hong-jing Cui ${ }^{4 *}$, \\ Guang-zhi Shen ${ }^{1}$, Miao-jing $\mathrm{Li}^{5}$, Jian-tao Lin $^{4 *}$ and Ya-xin Sun ${ }^{1 *}$ \\ ${ }^{1}$ Mudanjiang Medical College, Mudanjiang, China, ${ }^{2}$ The Second Tumor Department, Maoming People's Hospital, Maoming, \\ China, ${ }^{3}$ SSL Central Hospital of Dongguan City, Dongguan, China, ${ }^{4}$ Guangdong Provincial Key Laboratory of Medical Molecular, \\ Diagnostics Institute of Aging Research, Guangdong Medical University, Dongguan, China, ${ }^{5}$ School of Big Health and Intelligent \\ Engineering, Chengdu Medical College, Chengdu, China
}

By hydrothermal method, porous $\mathrm{TiO}_{2}$ spheres with pompon morphology are successfully synthesized in the tetrabutyl titanate (TBT)-acetic acid (HAc) system with no other additives. The morphological, structural and textural properties of the specimen are figured out by transmission electron microscopy (TEM), scanning electron microscopy (SEM), Fourier Transform Infrared Spectroscopy (FT-IR), X-ray powder diffraction (XRD), $\mathrm{N}_{2}$ adsorption/desorption, and fluorescence microscope. The results show the pomponlike morphology of porous $\mathrm{TiO}_{2}$ with high specific surface area and large pore volume, which can be used as a drug carrier. In this paper, doxorubicin hydrochloride (DOX) is chosen as drug model to understand the process of drug release. And results indicate that the porous $\mathrm{TiO}_{2}$ is biocompatible and can be used for continuing drug-release, which shows lots of possibilities in medical fields.

Keywords: $\mathrm{TiO}_{2}$, doxorubicin hydrochloride, drug release, drug delivery, drug carrier

\section{INTRODUCTION}

Porous material is a kind of network structure material composed of interconnected or closed holes, which is widely used in the field of drug delivery. Because of its large specific surface area, controllable pore size and functional modification, it can be loaded with different kinds of drug molecules and used in various drug delivery routes. For example, dexamethasone porous silicon particles can continuously release drugs to vitreous and retina (Hou et al., 2016), new porous polymer soluplus can improve the solubility of budesonide and make it absorbed through nasal cavity (Pozzoli et al., 2017), inhaled sildenafil poly (lactic co glycolic acid) (PLGA) porous particles can be used for the treatment of pulmonary hypertension and can reduce the dosage (Rashid et al., 2017) Polyaniline/porous silicon hybrid carrier loaded with doxorubicin hydrochloride for intravenous injection combined with photothermal therapy has a significant synergistic anti-tumor effect (Xia et al., 2017). By implanting lentivirus loaded macroporous sponge in the sheath for regeneration after spinal cord injury (Thomas et al., 2015), porous silicon dioxide lipid hybrid carrier can improve the dissolution rate of oral ibuprofen (Schultz et al., 2018). Among different kinds of porous materials, porous $\mathrm{TiO}_{2}$ has attracted enormous attention due to its high specific surface area, orderly structure, tunable pore size, favorable biocompatibility and easy-modified surface (Qin et al., 2011), which can be potentially applied to catalysis (Lorenz et al., 2006), sensing (Song et al., 2006a), biology (Li et al., 2009) and some other fields (Song et al., 2006b). To date, $\mathrm{TiO}_{2}$ with different morphologies, pore sizes (Ming et al., 2011), and structures (Li et al., 2009) have been extensively studied. Research on nanostructured porous material in drug release has been going on for over ten years. Thus, the advantages of such material and the effects of morphology on sustained-release performance have been systematically 
studied. Besides, the surface morphology of carrier material determines the contact area between carrier material and body fluids, and then influence sustained-release mechanisms. Therefore, it is greatly significant to develop novel $\mathrm{TiO}_{2}$ with diverse morphology used in drug-release field. Recently, the research of $\mathrm{TiO}_{2}$ materials as drug carriers mainly focuses on the $\mathrm{TiO}_{2}-\mathrm{P} 25$ nanoparticles (Song et al., 2006b; Ming et al., 2011; Zhang et al., 2012), functioned $\mathrm{TiO}_{2}$ nanoparticles (Yamaguchi et al., 2010; Naghibi et al., 2014; Du et al., 2015), and $\mathrm{TiO}_{2}$ nanotube arrays (Peng et al., 2009; Song et al., 2009; Shokuhfar et al., 2013; Xu et al., 2015). Some applications of $\mathrm{TiO}_{2}$ are being developed such as $\mathrm{Fe}_{3} \mathrm{O}_{4} @ \mathrm{TiO}_{2}$ nanoparticles with core-shell structure have been explored as drug carrier to inhibited the growth of ovarian carcinoma cells (Arora et al., 2012). So far, the application in medical treatment has been limited by the aggregation of the $\mathrm{TiO}_{2}$ nanoparticles, which causes the decline of photocatalytic reactivity and the low specificity of cancer cells. Some researches reveal that the problems mentioned above can be solved by coating $\mathrm{TiO}_{2}$ with silica or polyethylene glycol (PEG) to decrease the aggregation (Yamaguchi et al., 2010; Arora et al., 2012; Naghibi et al., 2014; Du et al., 2015). Folate can be grafted on the surface of $\mathrm{TiO}_{2}$ nanoparticles to conduct them toward target cells (Naghibi et al., 2014; Feng et al., 2015). In addition, $\mathrm{TiO}_{2}$ nanoparticles exhibit specific capability to conduct photodynamic and sonodynamic therapy. During the therapy, the reactive oxygen species is formed and induces cytotoxicity against cancer cells significantly (Lagopati et al., 2010; Yamaguchi et al., 2011; Ninomiya et al., 2012; Feng et al., 2015). Therefore, there will be better treatment for cancer by combining photodynamic therapy or sonodynamic therapy of $\mathrm{TiO}_{2}$ with drug loading (Song et al., 2006b; Naghibi et al., 2014; Shen et al., 2014). Besides, it is well known that the extent of the interface between the drug-carrying particle and body fluids is determined by the surface morphology which also has influence on drug-release kinetics. So, with different morphologies of $\mathrm{TiO}_{2}$ the relationship between drug-release properties and surface morphology can be figured out and that will be really helpful to develop more effective drug delivery. So far, there are only few reports on the preparation of porous $\mathrm{TiO}_{2}$ for drug loading. For example, mesoporous $\mathrm{TiO}_{2}$ whiskers could carry more doxorubicin hydrochloride (DOX) than $\mathrm{TiO}_{2}$ nanoparticles (Li et al., 2009). Jang et al. prepared mesoporous $\mathrm{TiO}_{2}$ hollow nanoparticles by template method, which could load large amount of camptothecin for the hollow cavity structure (Kim et al., 2012).

Herein, $\mathrm{TiO}_{2}$ sphere with pompon morphology has been successfully synthesized by a hydrothermal process. This special appearance morphology possesses high surface area which is essential for the mass transfer because it is easier for drugs to access to active-sites, which makes it favorable for $\mathrm{TiO}_{2}$ to load drugs.

\section{EXPERIMENTAL SECTION}

\section{Materials}

Tetrabutyl titanate (TBT) was purchased from Kermel (China). HAc was purchased from Xilong chemicals (China). DOX was purchased from Sigma-Aldrich (China). Carboxyfluorescein and
Quercetin were purchased from Aladdin (China). Congo red was purchased from BASF (China). Sudan IV and Rhodamine B were purchased from Guoyao Reagents (China). RPMI-1640 culture medium and fetal bovine serum (FBS) was purchased from Gibco (United States). All other reagents, including ethanol, $\mathrm{HCl}$, $\mathrm{K}_{2} \mathrm{HPO}_{4}, \mathrm{NaH}_{2} \mathrm{PO}_{4}$, and $\mathrm{NaOH}$ were purchased from Xilong chemicals (China). DOX, Carboxyfluorescein, Quercetin, Congo Red, Sudan IV, and Rhodamine B stock solutions were freshly prepared and stored in the dark at $4^{\circ} \mathrm{C}$. The ultrapure water was used in all experiments.

\section{Method}

\section{Synthesis of Porous $\mathrm{TiO}_{2}$ Spheres}

By following hydrothermal solvothermal method reported in the literature (Ye et al., 2010), porous $\mathrm{TiO}_{2}$ was easily synthesized with some modifications. Typically, $0.6 \mathrm{ml}$ of TBT was dropwise added to $30 \mathrm{ml}$ of HAc and the mixed solution was continually stirred for $10 \mathrm{~min}$. After that, the white suspension was transferred into $50 \mathrm{ml}$ Teflon-lined stainless-steel autoclave and kept in the oven for $3 \mathrm{~h}$ at $200^{\circ} \mathrm{C}$. After cooling down to room temperature, the product was collected by centrifugation, then washed with ethanol several times and dried at $60^{\circ} \mathrm{C}$ overnight. At last, the dried product was calcined at $450^{\circ} \mathrm{C}$ for $3 \mathrm{~h}$ to remove the residual organics. field-emission scanning electron microscope (SEM, SUPRA55 ZEISS, United States) and transmission electron microscopy (TEM, Tecnai-F30) were used to observe the morphology of samples. The fourier transform infrared (FT-IR) measurement was characterized by a Thermo Scientific Nicolet iS10 FT-IR Spectrometer (United States). X-ray powder diffraction (XRD) measurement was carried out with Rigaku D/max-2500 diffractometer with $\mathrm{Cu}$ $\mathrm{Ka}$ radiation $(\lambda=0.1542 \mathrm{~nm}, 40 \mathrm{kV}, 100 \mathrm{~mA})$. The specific surface area and pore size distribution of were obtained by the Brunauer-Emmett-Teller (BET, Micrometrics ASAP 2010) method through the detection of $\mathrm{N}_{2}$ adsorption desorption at $-196^{\circ} \mathrm{C}$. Before the test, the sample is degassed in vacuum. Energy dispersive spectroscopy (EDS, Oxford, Britain) was used to analysis chemical composition of samples.

\section{Drugs Adsorption by Porous $\mathrm{TiO}_{2}$ Spheres}

To measure adsorption capability towards drugs, $1 \mathrm{mg}$ asprepared $\mathrm{TiO}_{2}$ powder was dispersed in DOX $(3 \mathrm{ml}, 2 \mathrm{mmol})$ solutions. After that the samples were sealed immediately and soaked for $12 \mathrm{~h}$ under stirring in dark at $37^{\circ} \mathrm{C}$. Then the solution was centrifuged to get the supernatant which was later measured by UV-Vis absorption spectra, the sediment was collected and freeze-dried to get DOX loaded $\mathrm{TiO}_{2}$.

\section{Measurement of Drug Release}

The in vitro drug release test was performed as follows. $50 \mathrm{mg}$ DOX-TiO ${ }_{2}$ sample was placed into a dialysis membrane bag (molecular-weight cut off $5000 \mathrm{kDa}$ ) and then immersed in $20 \mathrm{ml}$ phosphate buffer solution ( $\mathrm{PBS}, \mathrm{pH}=7.4$ ) solution under gentle stirring in dark conditions at $37^{\circ} \mathrm{C}$. A certain amount of buffer solution was extracted at time intervals and the equal amount of fresh PBS was immediately injected into the original PBS solution to keep the volume of $20 \mathrm{ml}$. The amount of released DOX in the 

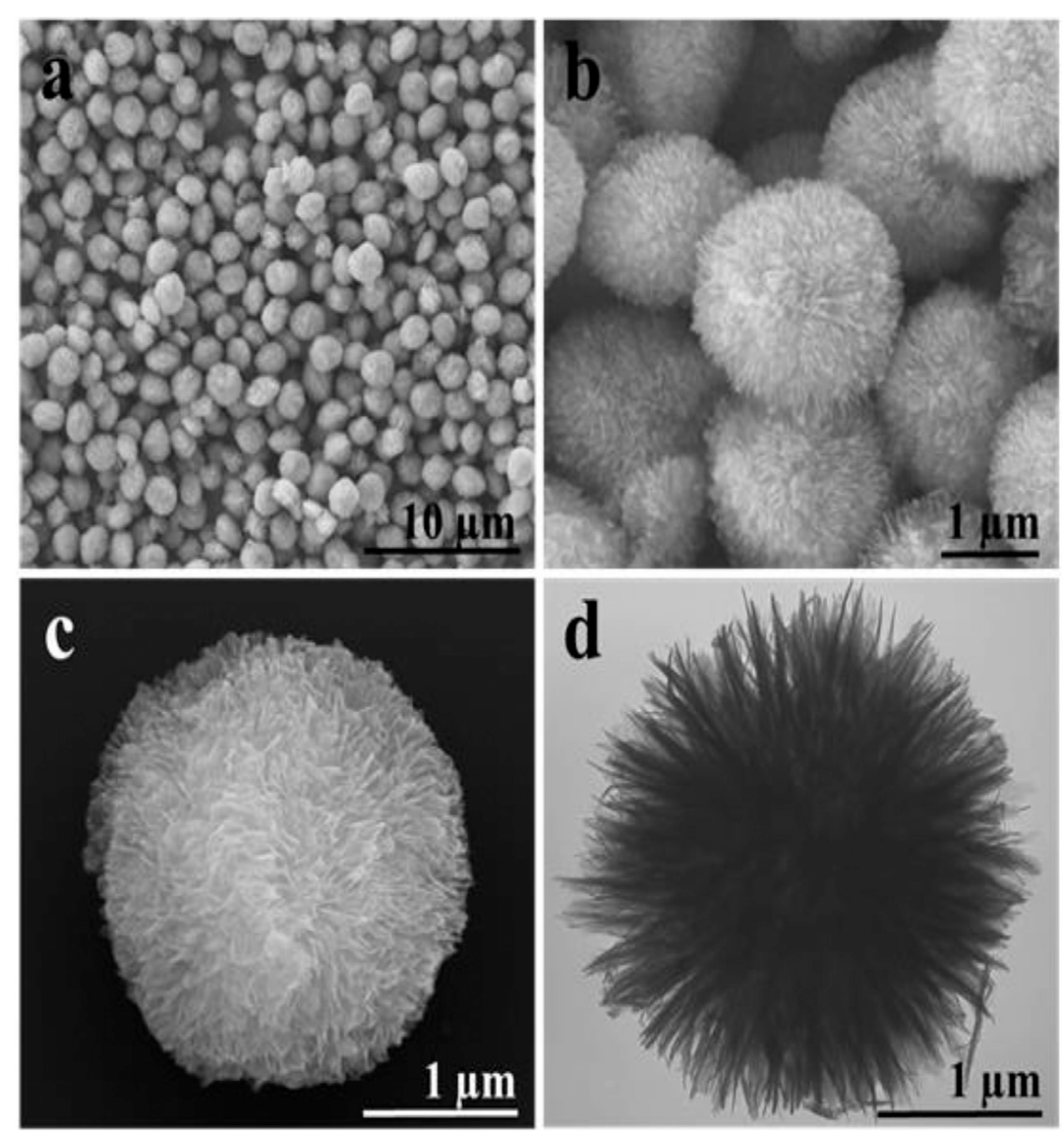

FIGURE 1 | (A-C) Scanning electron microscope and (D) transmission electron microscopy images of porous $\mathrm{TiO}_{2}$ spheres with different magnifications.

extracted PBS solution was measured by UV-vis spectrophotometry. Drug release rate was calculated based on the intensity of drugs by Ultraviolet-visible (UV-vis) absorption spectra (Agilent Cary 60, United States).

\section{Intracellular Release of Drug}

HeLa (human adenocarcinoma) cells were cultivated and maintained in RPMI-1640 medium with $10 \% \mathrm{FBS}$ at $37^{\circ} \mathrm{C}$ in an atmosphere of $5 \% \mathrm{CO}_{2}$, then cultured in 6 -well plates $(2.5 \times$ $10^{4}$ cells per well) for $24 \mathrm{~h}$. After being rinsed twice with PBS solution, $\mathrm{DOX}-\mathrm{TiO}_{2}$ was added into each well at a concentration of $20 \mathrm{mg} \mathrm{ml}^{-1}$. After being incubated for $24 \mathrm{~h}$ at $37^{\circ} \mathrm{C}$, the cells were rinsed with PBS and dyed with $10 \mathrm{mg} \mathrm{ml}^{-1}$ of Hoechst 33324 for $10 \mathrm{~min}$. Finally, the cells were washed twice with PBS and observed by fluorescence microscope. Fluorescence microscope (Nikon 80i, Japan) was used to take images of the samples.

\section{MTT Cytotoxicity Assay}

The HeLa cells were cultured in 96-well plate with 10,000 cells per well in $\mathrm{CO}_{2}$ incubator $\left(37^{\circ} \mathrm{C}, 5 \% \mathrm{CO}_{2}\right.$, saturated humidity) for $24 \mathrm{~h}$. Then $100 \mu \mathrm{l}$ RPMI-1640 culture medium with 10\% FBS and DOX- $\mathrm{TiO}_{2}$ spheres at different concentration $\left(\mathrm{DOX}-\mathrm{TiO}_{2}\right.$ and $\mathrm{TiO}_{2}$ with the same quantum of DOX, ranging from $0.1-5.0 \mu \mathrm{g}$ $\mathrm{ml}^{-1}$ ) was added $100 \mathrm{ml}$. Each concentration of nanoparticles was added to three wells. After culturing at $37^{\circ} \mathrm{C}$ for $24 \mathrm{~h}$, the supernatant was removed. Then RPMI-1640 culture medium with $100 \mu \mathrm{l} 0.5 \mathrm{mg}$ $\mathrm{ml}^{-1}$ MTT was added into each well to incubate at $37^{\circ} \mathrm{C}$ for $4 \mathrm{~h}$. After removing the supernatant, $150 \mu \mathrm{l}$ DMSO was added into each well. The result of absorbance (the wavelength of determination is $570 \mathrm{~nm}$ ) was obtained after cytolysis. HeLa cells incubated without nanoparticles were taken as the control groups, and cell viability was the standard to judge the cytotoxicity of nanoparticles.

\section{RESULTS AND DISCUSSION}

\section{Fabrication of $\mathrm{TiO}_{2}$ Spheres}

The morphology of $\mathrm{TiO}_{2}$ has an important influence on its drug loading and release. The $\mathrm{TiO}_{2}$ particles were produced with relatively uniform size as shown in Figure 1A. After zooming in, they are pompon-like spheres with a diameter of $\sim 2.0 \mu \mathrm{m}$. The highly porous structure of $\mathrm{TiO}_{2}$ spheres can be observed from the scanning electron microscope and transmission electron microscopy images with higher magnification (Figures 1B-D). Chemical composition analysis by Energy dispersive spectroscopy (Figure 2) illustrates that the porous spheres are composed of titanium and oxygen elements. The same synthesis method can sometimes form different morphology of $\mathrm{TiO}_{2}$, which is mainly related to some 

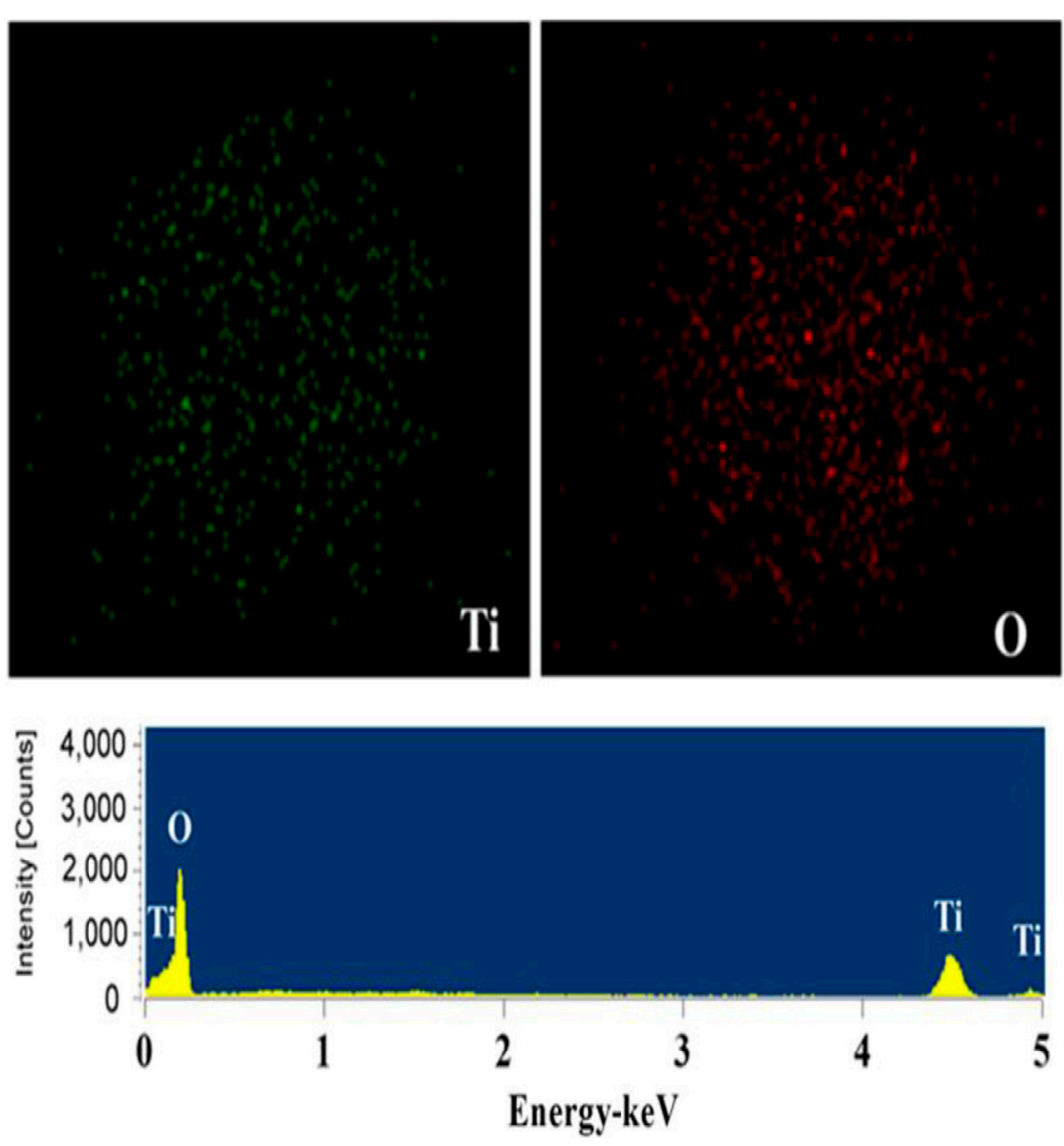

FIGURE 2 | Energy dispersive spectroscopy microanalysis spectrum of porous $\mathrm{TiO}_{2}$ spheres.

influencing factors. The common influencing factors are temperature, $\mathrm{pH}$ value, adding certain ions, reaction time, and so on. At present, the morphologies of $\mathrm{TiO}_{2}$ are spherical, microsphere, hollow sphere, flower, nanofiber, nanotube, flake, rod, etc. At this research, the pompon like $\mathrm{TiO}_{2}$ microspheres were synthesized by using ethanol as solvent at $200^{\circ} \mathrm{C}$ and the structure has not been reported before.

$$
\begin{aligned}
& \mathrm{Ti}\left(\mathrm{OC}_{4} \mathrm{H}_{9}\right)_{4}+x \mathrm{CH}_{3} \mathrm{COOH} \rightarrow\left(\mathrm{CH}_{3} \mathrm{COO}\right)_{\mathrm{x}} \mathrm{Ti}\left(\mathrm{OC}_{4} \mathrm{H}_{9}\right)_{4-\mathrm{x}} \\
& +x \mathrm{C}_{4} \mathrm{H}_{9} \mathrm{OH} \\
& \mathrm{C}_{4} \mathrm{H}_{9} \mathrm{OH}+\mathrm{CH}_{3} \mathrm{COOH} \rightarrow \mathrm{CH}_{3} \mathrm{COOC} \mathrm{H}_{9}+\mathrm{H}_{2} \mathrm{O} \\
& \equiv \mathrm{Ti}-\mathrm{OR}+\mathrm{H}_{2} \mathrm{O} \rightarrow \equiv \mathrm{Ti}-\mathrm{OH}+\mathrm{ROH} \\
& \left(\mathrm{R}=\mathrm{C}_{4} \mathrm{H}_{9} \text { or } \mathrm{CH}_{3} \mathrm{CO}\right) \\
& \equiv \mathrm{Ti}-\mathrm{OR}^{\prime}+\equiv \mathrm{Ti}-\mathrm{OR}^{\prime \prime} \rightarrow \equiv \mathrm{Ti}-\mathrm{O}-\mathrm{Ti} \equiv \mathrm{R}^{\prime} \mathrm{OR}^{\prime \prime} \\
& \left(\mathrm{R}^{\prime}=\mathrm{H} \text { or } \mathrm{CH}_{3} \mathrm{CO} ; \mathrm{R}^{\prime \prime} \mathrm{H} \text { or } \mathrm{C}_{4} \mathrm{H}_{9}\right)
\end{aligned}
$$

\section{Route 1 Synthesis of $\mathrm{TiO}_{2}$}

A tentative mechanism for the formation of anatase $\mathrm{TiO}_{2}$ mesocrystals was proposed as illustrated in Route 1 . In the current solvothermal synthesis at $200^{\circ} \mathrm{C}$, the reaction between $\mathrm{Ti}\left(\mathrm{OC}_{4} \mathrm{H}_{9}\right)_{4}$ and HAc first resulted in the coordination of HAc to titanium centers to form unstable titanium acetate complexes $\left(\mathrm{CH}_{3} \mathrm{COO}\right) \times \mathrm{Ti}\left(\mathrm{OC}_{4} \mathrm{H}_{9}\right)_{4}-\mathrm{x}$ by ligand exchange/substitution, concomitant with the release of $\mathrm{C}_{4} \mathrm{H}_{9} \mathrm{OH}$ (Eq. 1). The produced $\mathrm{C}_{4} \mathrm{H}_{9} \mathrm{OH}$ could then react with the solvent HAc to form water by a slow esterification reaction (Eq. 2). Subsequently, Ti-O-Ti bonds would form by both hydrolysis-condensation and nonhydrolytic condensation processes (Eqs 3,4) leading to the formation of crystallized pompon-like $\mathrm{TiO}_{2}$. In the current situation, the nascent anatase nanocrystals with high surface energies might be temporarily stabilized by acetic acid, which could then orient each other to form a crystallographic oriented mesocrystalline architecture with some butyl acetate enwrapped in the interparticle pores. Finally, nanoporous anatase $\mathrm{TiO}_{2}$ mesocrystals with preserved morphology will result from removal of the organic residuals by subsequent calcination, accompanied by a moderate increase in the size of the nanocrystal subunits. During the mesoscale assembly of the pomponlike-shaped, anatase mesocrystals with a single-crystal-like structure, the solvent acetic acid played multiple roles. First, it acted as the chemical modifier of TBT to lower its reactivity. Second, it reacted with TBT to form transient or metastable precursors for slow release of soluble titanium-containing species for the continuous formation of nascent anatase nanocrystals. Third, it acted as the stabilizing solvent to temporarily stabilize the tiny anatase nanocrystals against immediate single crystal formation or uncontrolled aggregation, but the binding to the $\{001\}$ facets was relative weak, so that the subsequent oriented attachment along the [001] direction could 


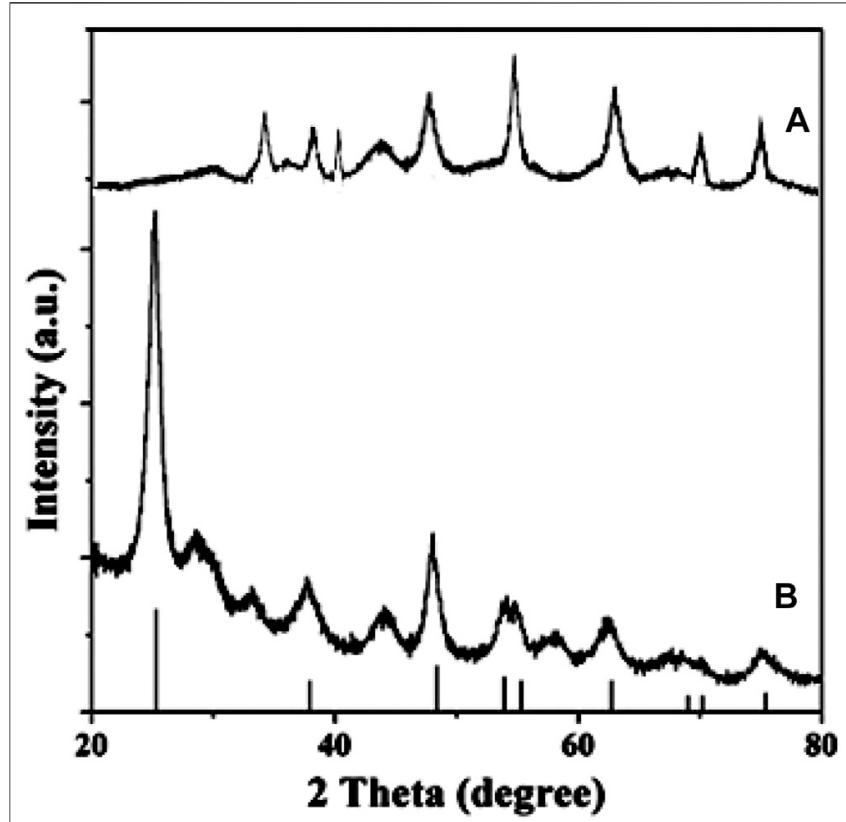

FIGURE 3 |X-ray powder diffraction pattern of the Titanium sheet (A) and porous $\mathrm{TiO}_{2}$ microspheres (B).

take place readily. Fourth, it reacted with TBT to produce butyl acetate that played the role of porogen or template during the oriented aggregation of anatase nanocrystals to form mesocrystals (Ye et al., 2010).

It can be seen from the Figure 3 that both have the characteristic diffraction absorption peak of Ti: $2 \theta=35.2^{\circ}$, $38.6^{\circ}, 40.3^{\circ}, 53.1^{\circ}, 63.0^{\circ}$, this is caused by the titanium substrate. Different from Figure 3A, new peaks appears at $2 \theta$ $=25.2^{\circ}, 37.9^{\circ}, 47.8^{\circ}, 53.9^{\circ}, 54.9^{\circ}$ in Figure 3B. This is the characteristic absorption peak of $\mathrm{TiO}_{2}$ anatase, which may be due to the transformation of $\mathrm{TiO}_{2}$ from amorphous to anatase after hydrothermal treatment.

\section{Drug Loading Properties}

In order to clarify the relationship between the carrier and the drug, we used FT-IR spectroscopy to detect the sample. The FTIR spectra of $\mathrm{TiO}_{2}, \mathrm{DOX}-\mathrm{TiO}_{2}$, and pure DOX are presented in Figure 4. The bands at 3,425 is attributed to the stretching mode and the "scissor"-bending mode of $-\mathrm{OH}$, respectively, which come from $\mathrm{H}_{2} \mathrm{O}$ absorbed on the surface of the products and $-\mathrm{OH}$ on the surface of $\mathrm{TiO}_{2}$ (Chen et al., 2009). The absorption band at $690 \mathrm{~cm}^{-1}$ is attributed to Ti-O stretching vibration (Chen et al., 2009; Cui M. et al., 2012). The bands at 1641 and $1500 \mathrm{~cm}^{-1}$ may attributed to $\mathrm{C}=\mathrm{O}$ and $\mathrm{C}-\mathrm{O}-\mathrm{C}$ of by products of the reaction as route 1 showed (Ye et al., 2010). Two characteristic absorption peaks at 1619 and $1580 \mathrm{~cm}^{-1}$ are ascribed to the stretching vibration of $\mathrm{C}=\mathrm{O}$ from the anthraquinone ring of DOX. The peaks at 993 and $2930 \mathrm{~cm}^{-1}$ are assigned to the $\mathrm{C}-\mathrm{O}-\mathrm{C}$ and $\mathrm{CH}_{3}$ stretching vibration of DOX, respectively. The couple of the peaks are also observed in $\mathrm{DOX}-\mathrm{TiO}_{2}$, and no new bands are observed. According to the results, it can be speculated that DOX is loaded onto $\mathrm{TiO}_{2}$ surface mainly through noncovalent bond.

\section{In vitro and Intracellular Release of Drugs}

It is accepted that the DOX molecules are entrapped within the pores by immersing process and liberated via a diffusioncontrolled manner. In addition, the hydroxyl, carboxyl, and carbonyl groups in drug molecules can form hydrogen bonding with $\mathrm{Ti}-\mathrm{OH}$ groups on the porous $\mathrm{TiO}_{2}$ surface. At the drug release stage, PBS solution carry the drugs out of $\mathrm{TiO}_{2}$ pores by dissolving the drugs. Before the dynamic concentration equilibrium is achieved, the continuous drug release is conducted by diffusion-controlled manner which maily depends on the dynamic equilibrium between the drug concentration inside the pores and the drug concentration in the bulk solution in PBS. Thus, a sustained drug release stage is reached.

Figure 6A shows the drug-release result of $\mathrm{DOX}-\mathrm{TiO}_{2}$ in simulated body fluid and in cells. As for drug-release research in vitro, the process of releasing DOX molecules seen from Figure 6A can be divided into two stages: fast release stage for the first $3 \mathrm{~h}$ and continuing release stage in the following $21 \mathrm{~h}$

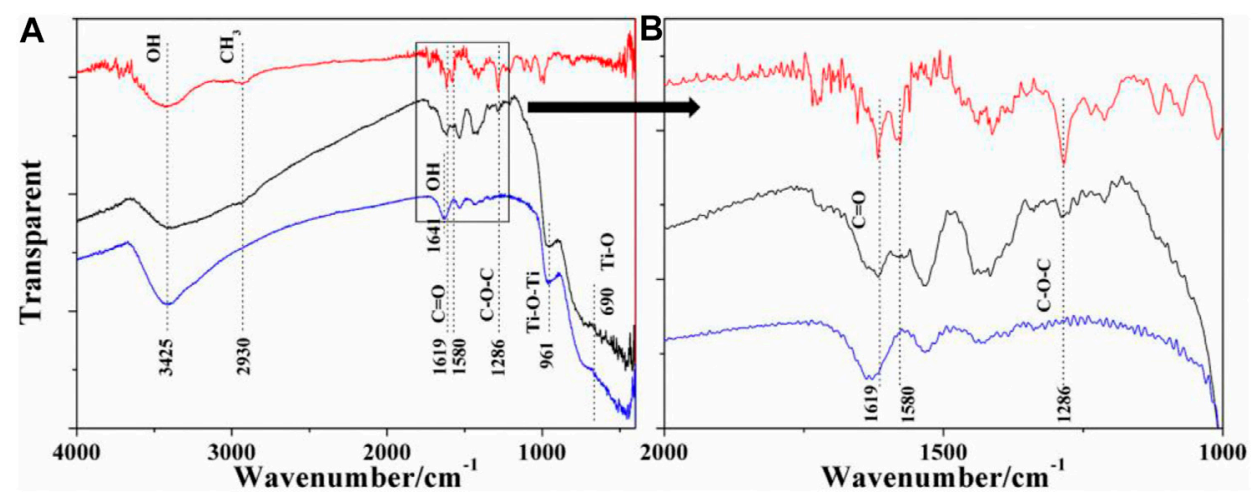

FIGURE 4 | (A) FT-IR spectra of $\mathrm{TiO}_{2}$ (blue), DOX- $\mathrm{TiO}_{2}$ (black), and pure DOX (red). (B) magnification of rectangular box in (A). 


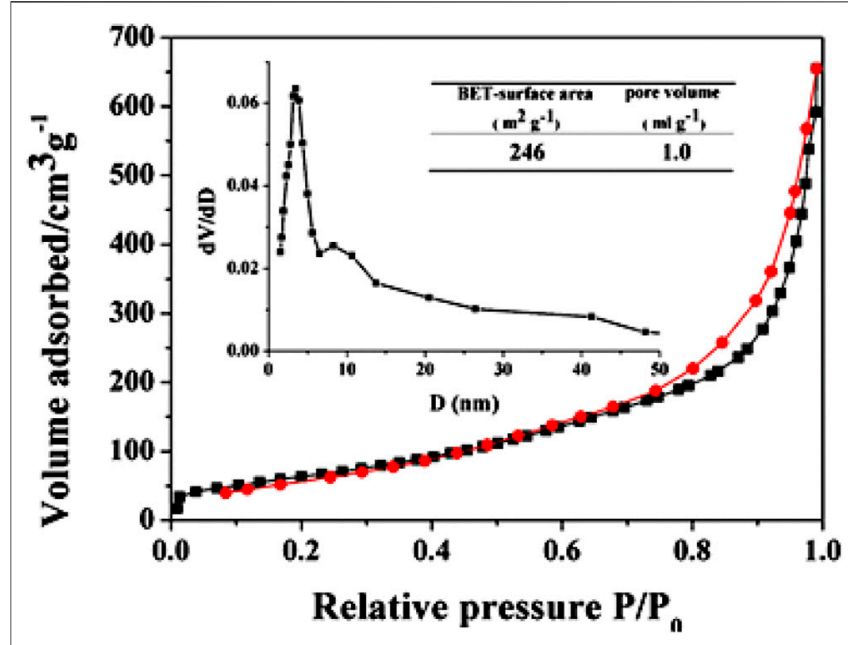

FIGURE 5 | Adsorption-desorption isotherms of the representative the porous $\mathrm{TiO}_{2}$ microspheres. Inset shows the pore size distribution obtained from the adsorption branch.

Certain amount of drug molecules can be absorbed onto the surface of $\mathrm{TiO}_{2}$ spheres via physical effects. However, due to the weak absorption of the drug molecules, the drugs will quickly dissolve into buffer solution and initiate the fast release stage once contacting with buffer solution. After that, drugs absorbed into pores or on the surface of $\mathrm{TiO}_{2}$ spheres by strong hydrogen bonds continue slowly releasing, which induces the second stage and lasts for $21 \mathrm{~h}$. Obviously, $\mathrm{TiO}_{2}$ spheres has the ability of drug storage and slow release. Besides, the initial fast release stage of DOX molecules is important for the treatment of cancer since the amount of released drugs is larger, which can rapidly inhibit multiplication of cancer cells. The rest of cancer cells will gradually die during the process of continual drug releasing. Therefore, the system of $\mathrm{DOX}-\mathrm{TiO}_{2}$ is promising in cancer treatment. This release behavior is similar to the drug release behavior in $\mathrm{TiO}_{2}$ nanotubes, both of which are rapid release at the beginning and slow release afterwards. However, compared with titanium dioxide nanotubes, because the surface area of nanotubes is larger and the more drug is adsorbed (Figure 5), its rapid release period and slow release period are longer (Moseke et al., 2012). We fitted the drug release data and found that the drug release was suitable for the first-order kinetic equation, the fitted equation is:

$\ln \left(1-\mathrm{M}_{\mathrm{t}} / \mathrm{M}_{\infty}\right)=-0.3369 \mathrm{t}-0.4369$, the correlation coefficient $\mathrm{R}=0.99$

This indicates that the drug release is completed by DOX dissolution and desorption, and that the drug loading is completed by adsorption without chemical reaction, which is consistent with the previous analysis; The amount of drug release per unit time was less and less with the extension of time.

To visualize the cellular uptake of $\mathrm{TiO}_{2}$ spheres and the intracellular distribution of DOX, the samples are readily characterized by optical microscopy. After incubation for $24 \mathrm{~h}$ at $37^{\circ} \mathrm{C}$, observations reveal that nearly all cells contain DOX- $-\mathrm{TiO}_{2}$ spheres, which shows that microspheres can be
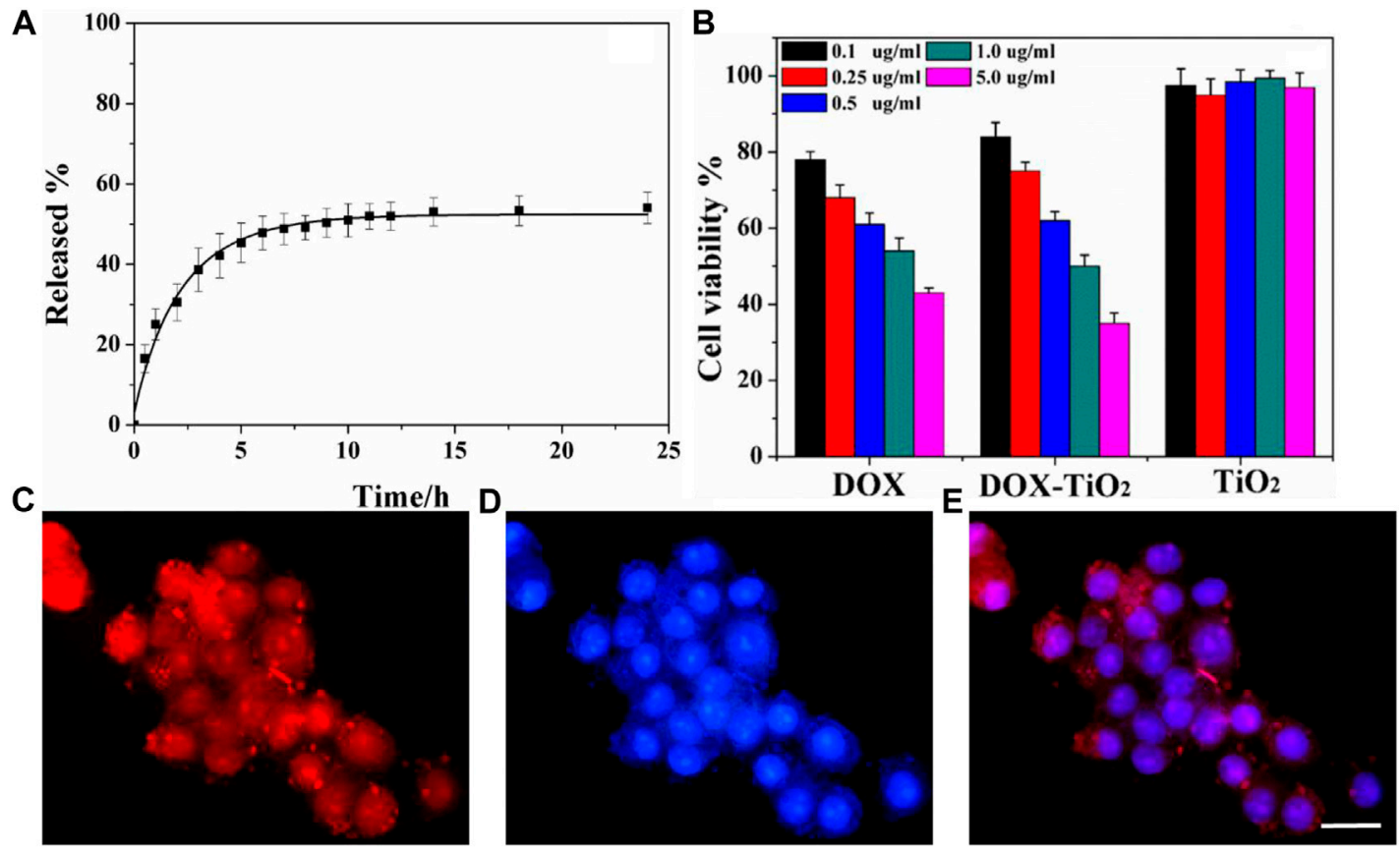

FIGURE 6 | (A) Drug-release profile for DOX-TiO 2 in PBS buffer. (B) HeLa cells incubated with DOX, DOX-TiO 2 , and TiO 2 (C) Representative deconvolution microscope images of HeLa cells treated with $\mathrm{DOX}-\mathrm{TiO}_{2}$. Red fluorescence arises from DOX; Highlight red fluorescence dot corresponds to DOX-TiO ${ }_{2}$ ( (D) Nuclei were stained blue with Hoechst 33342; (E) Merged image of Hoechst, DOX, and DOX- $\mathrm{TiO}_{2}$ signals. Scale bars is $20 \mu \mathrm{m}$. 
taken in by HeLa cell, similar as previous reports (Cui J. et al., 2012; Chen et al., 2014). Accumulation of red fluorescence in the cell nuclei is apparent to observe, which shows that nearly all of the nuclei contains DOX. DOX-associated fluorescence images are also presented in the cytoplasm (Figures $6 \mathrm{C}-\mathrm{E}$ ), and this suggests that DOX has been released from $\mathrm{DOX}-\mathrm{TiO}_{2}$ samples.

\section{MTT Cytotoxicity Assay}

MTT is applied to analyze and study the cell activity, and the result is showed in Figure 6B. Besides that, pure DOX at the same concentration is also added into the medium to culture cells, and the cell viability is detected by MTT. The results indicate that within the limits of consistency the activity of cells incubated by $\mathrm{TiO}_{2}$ spheres culture medium maintains $100 \%$, which manifests that pure $\mathrm{TiO}_{2}$ spheres has great biocompatibility. That is to say that this kind of material is nontoxic, and can be applied to the biomedical field. For the cells incubated in $\mathrm{DOX}-\mathrm{TiO}_{2}$ medium, at low concentration cell viability of the system is higher than that of cells incubated in pure DOX medium, while at high concentration cell viability of the system is higher than that of cells incubated in pure DOX medium, which may be due to the different modes to enter cells. The mode of DOX to enter cells is the diffusion, and the mode of $\mathrm{DOX}-\mathrm{TiO}_{2}$ to enter cells is endocytosis. So the speed of DOX's entering cells is faster than that of $\mathrm{DOX}-\mathrm{TiO}_{2}$, which accounts for the higher cytotoxicity of DOX at low concentration. At high concentration, $\mathrm{DOX}-\mathrm{TiO}_{2}$ is transferred into cancer by endocytosis, and then DOX is released gradually to kill the cancer cells.

\section{CONCLUSION}

According to the results of the experiments, some conclusions can be summarized that porous $\mathrm{TiO}_{2}$ with pompon-like sphere morphology can be synthesized by hydrothermal method and the prepared material has lots of excellent physical properties, including high specific surface area, large pore volume, and

\section{REFERENCES}

Arora, H. C., Jensen, M. P., Yuan, Y., Wu, A., Vogt, S., Paunesku, T., et al. (2012). Nanocarriers Enhance Doxorubicin Uptake in Drug-Resistant Ovarian Cancer Cells. Cancer Res. 72, 769-778. doi:10.1158/0008-5472.can-11-2890

Chen, K.-S., Liu, P.-Y., Hung, T.-S., Liao, S.-C., Chen, S.-C., Lin, H.-R., et al. (2009). Preparation of Titanium Oxide-Containing Organic Film by Dipping Ti(OR)4 and Cold Plasma Oxidizing on PET. Appl. Surf. Sci. 256, 1101-1105. doi:10. 1016/j.apsusc.2009.05.170

Chen, X., Yan, Y., Müllner, M., van Koeverden, M. P., Noi, K. F., Zhu, W., et al. (2014). Engineering Fluorescent Poly(dopamine) Capsules. Langmuir 30, 2921-2925. doi:10.1021/la4049133

Cui, J., Yan, Y., Such, G. K., Liang, K., Ochs, C. J., Postma, A., et al. (2012). Immobilization and Intracellular Delivery of an Anticancer Drug Using Mussel-Inspired Polydopamine Capsules. Biomacromolecules 13, 2225-2228. doi:10.1021/bm300835r

Cui, M., Tian, S., Zhao, H., Jin, R., Chen, Y., Liu, B., et al. (2012). Solvothermal Synthesis and Enhanced Photocatalytic Activity of Flowerlike Nanoarchitectures Assembled from Anatase TiO2 Nanoflakes. Phys. E: LowDimens. Syst. Nanostruct. 44, 2110-2117. doi:10.1016/j.physe.2012.06.025

Du, Y., Ren, W., Li, Y., Zhang, Q., Zeng, L., Chi, C., et al. (2015). The Enhanced Chemotherapeutic Effects of Doxorubicin Loaded PEG Coated TiO2 pompon-like sphere morphology. The drug-release property of $\mathrm{TiO}_{2}$ spheres is chartered by DOX-released test, and the results show its great drug sustained-release properties.

\section{DATA AVAILABILITY STATEMENT}

The original contributions presented in the study are included in the article/Supplementary Material, further inquiries can be directed to the corresponding authors.

\section{AUTHOR CONTRIBUTIONS}

All authors listed have made a substantial, direct, and intellectual contribution to the work and approved it for publication.

\section{FUNDING}

This work was supported by the National Natural Science Foundation of China (Grant Nos. 31701050, 81373083, 81573216), the funds for basic scientific research of Universities in Heilongjiang Province (Grant Nos. 2017-KYYWFMY-0671, 2018KYYWFMY0018, 2018KYYWFMY0089), Foundation of Maoming Science and Technology Plan (mmjk2020018) and Foundation of High-level Hospital Construction Research Project of Maoming People's Hospital, Higher education teaching reform research project of Mudanjiang Medical College in 2019 (Grant No. myzd20190002), Project of Collaborative Innovation Center of Sichuan for Elderly Care and Health (No: YLZB2004), Program of Chengdu Science and Technology Bureau (No: 2020-RK00-00042-ZF), Scientific Research Project of Chengdu Medical College (No: CYZYB20-02), Foundation of South China Sea for R\&D Marine Biomedicine Resources (2HC18014).

Nanocarriers in an Orthotopic Breast Tumor Bearing Mouse Model. J. Mater. Chem. B 3, 1518-1528. doi:10.1039/c4tb01781a

Feng, X., Zhang, S., Wu, H., and Lou, X. (2015). A Novel Folic Acid-Conjugated TiO2-SiO2 Photosensitizer for Cancer Targeting in Photodynamic Therapy. Colloids Surf. B: Biointerfaces 125, 197-205. doi:10.1016/j.colsurfb.2014.11.035

Hou, H., Wang, W., Nan, K., Freeman, W. R., Sailor, M. J., and Cheng, L. (2016) Controlled Release of Dexamethasone from an Intravitreal Delivery System Using Porous Silicon Dioxide. Invest. Opthalmology Vis. Sci. 57 (2), 557-566. doi:10.1167/iovs.15-18559

Kim, C., Kim, S., Oh, W. K., Choi, M., and Jang, J. (2012). Efficient Intracellular Delivery of Camptothecin by Silica/titania Hollow Nanoparticles. Chem. Eur. J. 18, 4902-4908. doi:10.1002/chem.201200043

Lagopati, N., Kitsiou, P. V., Kontos, A. I., Venieratos, P., Kotsopoulou, E., Kontos, A. G., et al. (2010). Photo-induced Treatment of Breast Epithelial Cancer Cells Using Nanostructured Titanium Dioxide Solution. J. Photochem. Photobiol. A: Chem. 214, 215-223. doi:10.1016/j.jphotochem.2010.06.031

Li, Q., Wang, X., Lu, X., Tian, H., Jiang, H., Lv, G., et al. (2009). The Incorporation of Daunorubicin in Cancer Cells through the Use of Titanium Dioxide Whiskers. Biomaterials 30, 4708-4715. doi:10.1016/j.biomaterials.2009.05.015

Lorenz, M. R., Holzapfel, V., Musyanovych, A., Nothelfer, K., Walther, P., Frank, H., et al. (2006). Uptake of Functionalized, Fluorescent-Labeled Polymeric Particles in Different Cell Lines and Stem Cells. Biomaterials 27, 2820-2828. doi:10.1016/j.biomaterials.2005.12.022 
Ming, H., Ma, Z., Huang, H., Lian, S., Li, H., He, X., et al. (2011). Nanoporous TiO2 Spheres with Narrow Pore Size Distribution and Improved Visible Light Photocatalytic Abilities. Chem. Commun. 47, 8025-8027. doi:10.1039/ clcc12557e

Moseke, C., Hage, F., Vorndran, E., and Gbureck, U. (2012). TiO2 Nanotube Arrays Deposited on Ti Substrate by Anodic Oxidation and Their Potential as a Long-Term Drug Delivery System for Antimicrobial Agents. Appl. Surf. Sci. 258, 5399-5404. doi:10.1016/j.apsusc.2012.02.022

Naghibi, S., Madaah Hosseini, H. R., Faghihi Sani, M. A., Shokrgozar, M. A., and Mehrjoo, M. (2014). Mortality Response of Folate Receptor-Activated, PEGFunctionalized TiO2 Nanoparticles for Doxorubicin Loading with and without Ultraviolet Irradiation. Ceramics Int. 40, 5481-5488. doi:10.1016/j.ceramint. 2013.10.136

Ninomiya, K., Ogino, C., Oshima, S., Sonoke, S., Kuroda, S.-i., and Shimizu, N. (2012). Targeted Sonodynamic Therapy Using Protein-Modified TiO2 Nanoparticles. Ultrason. Sonochem. 19, 607-614. doi:10.1016/j.ultsonch.2011.09.009

Peng, L., Mendelsohn, A. D., LaTempa, T. J., Yoriya, S., Grimes, C. A., and Desai, T. A. (2009). Long-term Small Molecule and Protein Elution from TiO2 Nanotubes. Nano Lett. 9, 1932-1936. doi:10.1021/nl9001052

Pozzoli, M., Traini, D., Young, P. M., Sukkar, M. B., and Sonvico, F. (2017). Development of a Soluplus Budesonide Freeze-Dried Powder for Nasal Drug Delivery. Drug Development Ind. Pharm. 43, 1-31. doi:10.1080/03639045.2017.1321659

Qin, Y., Sun, L., Li, X., Cao, Q., Wang, H., Tang, X., et al. (2011). Highly WaterDispersible TiO2 Nanoparticles for Doxorubicin Delivery: Effect of Loading Mode on Therapeutic Efficacy. J. Mater. Chem. 21, 18003-18010. doi:10.1039/ cljm13615a

Rashid, J., Patel, B., Nozik-Grayck, E., Mcmurtry, I. F., Stenmark, K. R., and Ahsan, F. (2017). Inhaled Sildenafil as an Alternative to Oral Sildenafil in the Treatment of Pulmonary Arterial Hypertension (PAH). J. Controlled Release 250, 96-106. doi:10.1016/j.jconrel.2017.02.003

Schultz, H. B., Thomas, N., Rao, S., and Prestidge, C. A. (2018). Supersaturated Silica-Lipid Hybrids (Super-SLH): An Improved Solid-State Lipid-Based Oral Drug Delivery System with Enhanced Drug Loading. Eur. J. Pharm. Biopharm. 125, 13-20. doi:10.1016/j.ejpb.2017.12.012

Shen, S., Guo, X., Wu, L., Wang, M., Wang, X., Kong, F., et al. (2014). Dual-core@ shell-structured Fe3O4-NaYF4@TiO2 Nanocomposites as a Magnetic Targeting Drug Carrier for Bioimaging and Combined ChemoSonodynamic Therapy. J. Mater. Chem. B 2, 5775-5784. doi:10.1039/ c4tb00841c

Shokuhfar, T., Sinha-Ray, S., Sukotjo, C., and Yarin, A. L. (2013). Intercalation of Anti-inflammatory Drug Molecules within TiO2 Nanotubes. RSC Adv. 3, 17380-17386. doi:10.1039/c3ra42173b

Song, M., Pan, C., Li, J., Wang, X., and Gu, Z. (2006). Electrochemical Study on Synergistic Effect of the Blending of Nano TiO2 and PLA Polymer on the Interaction of Antitumor Drug with DNA. Electroanalysis 18, 1995-2000. doi:10.1002/elan.200603613
Song, M., Zhang, R., Dai, Y., Gao, F., Chi, H., Lv, G., et al. (2006). The In Vitro Inhibition of Multidrug Resistance by Combined Nanoparticulate Titanium Dioxide and UV Irradition. Biomaterials 27, 4230-4238. doi:10.1016/j. biomaterials.2006.03.021

Song, Y.-Y., Schmidt-Stein, F., Bauer, S., and Schmuki, P. (2009). Amphiphilic TiO2 Nanotube Arrays: an Actively Controllable Drug Delivery System. J. Am. Chem. Soc. 131, 4230-4232. doi:10.1021/ja810130h

Thomas, A. M., Palma, J. L., and Shea, L. D. (2015). Sponge-mediated Lentivirus Delivery to Acute and Chronic Spinal Cord Injuries. J. Controlled Release 204, 1-10. doi:10.1016/j.jconrel.2015.02.032

Xia, B., Wang, B., Shi, J., Zhang, Y., Zhang, Q., Chen, Z., et al. (2017). Photothermal and Biodegradable Polyaniline/porous Silicon Hybrid Nanocomposites as Drug Carriers for Combined Chemo-Photothermal Therapy of Cancer. Acta Biomater. 51, 197-208. doi:10.1016/j.actbio.2017.01.015

Xu, J., Zhou, X., Gao, Z., Song, Y. Y., and Schmuki, P. (2015). Visible-LightTriggered Drug Release from TiO2 Nanotube Arrays: A Controllable Antibacterial Platform. Angew. Chem. 55. doi:10.1002/anie.201508710

Yamaguchi, S., Kobayashi, H., Narita, T., Kanehira, K., Sonezaki, S., Kubota, Y., et al. (2010). Novel Photodynamic Therapy Using Water-Dispersed TiO2Polyethylene Glycol Compound: Evaluation of Antitumor Effect on Glioma Cells and Spheroids In Vitro. Photochem. Photobiol. 86, 964-971. doi:10.1111/j. 1751-1097.2010.00742.x

Yamaguchi, S., Kobayashi, H., Narita, T., Kanehira, K., Sonezaki, S., Kudo, N., et al. (2011). Sonodynamic Therapy Using Water-Dispersed TiO2-Polyethylene Glycol Compound on Glioma Cells: Comparison of Cytotoxic Mechanism with Photodynamic Therapy. Ultrason. Sonochem. 18, 1197-1204. doi:10.1016/ j.ultsonch.2010.12.017

Ye, J., Liu, W., Cai, J., Chen, S., Zhao, X., Zhou, H., et al. (2010). Nanoporous Anatase TiO2 Mesocrystals: Additive-free Synthesis, Remarkable Crystallinephase Stability, and Improved Lithium Insertion Behavior. J. Am. Chem. Soc. 133, 933-940. doi:10.1021/ja108205q

Zhang, H., Wang, C., Chen, B., and Wang, X. (2012). Daunorubicin-TiO2 Nanocomposites as a "smart" $\mathrm{pH}$-Responsive Drug Delivery System. Int. J. Nanomed. 7, 235-242. doi:10.2147/IJN.S27722

Conflict of Interest: The authors declare that the research was conducted in the absence of any commercial or financial relationships that could be construed as a potential conflict of interest.

Copyright (c) 2021 Cui, Chen, Ye, Cui, Cui, Cui, Shen, Li, Lin and Sun. This is an open-access article distributed under the terms of the Creative Commons Attribution License (CC BY). The use, distribution or reproduction in other forums is permitted, provided the original author(s) and the copyright owner(s) are credited and that the original publication in this journal is cited, in accordance with accepted academic practice. No use, distribution or reproduction is permitted which does not comply with these terms. 